\title{
MENSTRUAL HYGIENE PRACTICE AND SCHOOL ABSENTEEISM AMONG RURAL ADOLESCENT GIRLS OF KALIKOT DISTRICT
}

\author{
Ranabhat $D,{ }^{1}$ Nepal $S,{ }^{2}$ Regmi $B,{ }^{1}$
}

${ }^{1}$ Youth for Peace, Pepsicola and ${ }^{2}$ Om Health Campus, Chabahil, Kathmandu, Nepal

\begin{abstract}
Menstruation is a part of female reproductive cycle that starts when girls become sexually mature at the time of puberty. This study sought to assess the menstrual hygiene practice and school absenteeism among the rural school going adolescent girls. A descriptive cross-sectional study was done among 321 female high school students of 4 selected government schools of Kalikot a rural district of Nepal. It was found that majority of student's menstrual hygiene practice was poor i.e. $86.9 \%$. Majority of respondents (96\%) used clean cloth during their menstruation cycle, whereas only $4 \%$ of respondents used sanitary pad. Almost every adolescent girl i.e. $98.8 \%$ practiced any cultural restriction. Nearly 1 in 4 respondents $(22.1 \%)$ did not attend school during their last menstruation and more than 1 in 10 adolescent girls felt that their academic performance was degraded after menarche. Adolescent girls of 10-14 age group were three time more likely to have poor practice than those who were between 15-19 years. Adolescent girls from nuclear families are 1.9 times more likely to be absent from school during the menstrual cycle in comparison to girls from joint families. The study revealed that among the adolescent girls of the study area, the overall menstrual hygiene practice was found to be poor and the various beliefs were found to be inappropriate and school absenteeism was also prevalent during menstrual cycle.
\end{abstract}

\section{KEYWORDS}

Menstrual hygiene, school absenteeism, adolescent girls

\section{CORRESPONDING AUTHOR}

Deepmala Rana Bhat

Youth for Peace, Pepsicola,

Kathmandu, Nepal

Email: deepmalaranabhat@gmail.com

ORCID ID: 0000-0002-9291-0196

DOI: https://doi.org10.3126/nmcj.v21i4.27614 


\section{INTRODUCTION}

The onset of menstruation represents a landmark event in pubertal development of the adolescent girl. ${ }^{1}$ Menstruation is a significant part of women's reproductive cycle when a girl become sexually mature at the time of puberty and it lasts from 3-7 days whereas the onset of menstruation differs with race and family but mostly girls start from 10 to 14 years until 45 to 55 years and a women will have approximately 500 periods during her life time. ${ }^{2}$ This experience by women adds a useful asset to the evaluation of normal development and the elimination of pathological conditions, and it is one of the determinants of a woman's reproductive health. ${ }^{3,4}$ Menarche present a peculiar challenge to schooling, particularly as more girls stay in school at ages beyond the onset of puberty. ${ }^{5}$ A study from UNICEF showed that among the total respondent 1 out of 3 girls in South Asia knew nothing about menstruation before getting it while $48 \%$ of girls in Iran and $10 \%$ of girls in India believed that menstruation is a disease. ${ }^{6}$ Menstruation is linked with various misconceptions and wrong practices although it is a natural process, which might result in negative health outcome. Poor menstruation hygiene has been associated with serious health conditions such as reproductive tract and urinary tract infections. ${ }^{7}$ Monthly cycle is regarded to be unclean in Nepalese community, as a result menstruation is a negative, frightening experience, a disturbance, or is something to fear or to be embarrassed of, Confinements of day by day activities, for example, not being permitted to clean up, change garments, brush hair and enter sacred spots and dietary limitations (taboo on consumption of food like rice, curd, milk, potato, onion, sugarcane and so forth) are additionally imposed during the menstrual period. ${ }^{8}$ There are numerous difficulties during this period such as understanding self, the difficulties of family relationship and counselling, the challenges of peer pressure, and the difficulties of physical and sexual development. ${ }^{9,10}$ This study is planned to assess adolescent girls' knowledge of monthly cycle and also their practices of menstrual hygiene.

\section{MATERIALS AND METHODS}

Descriptive cross-sectional study was done. Purposive sampling was done to select the research area which was Raskot Municipality of Kalikot and 4 secondary schools were selected randomly in the study. Census was done to collect data. Total 321 students from the age group 10 to 19 years and those who already had menarche were only included and interviewed in the study. Data were collected from those students who were present during the time of data collection. A predesigned, pre-tested semi-structured questionnaire was used for data collection. Approval from Nepal Health Research Council for the research was obtained. Data were entered and analyzed using Statistical Package for Social Sciences (SPSS) 16.0 version. Statistical significance was considered at ( $P<0.05)$, high significance was considered if less than 0.01 , or insignificant if it is more than 0.05 . Univariate analysis was done to assess menstrual hygiene practice. Menstrual hygiene practice was calculated adding 11 answers to questions where each correct practice was scored 1 and wrong practice 0 , out of total 11 score, those who scored $\leq 6$ were recorded to have poor practice whereas those who scored $\geq 7$ were recorded to have good menstrual hygiene practice. Bivariate analysis was performed to show association between socio-demographic variable and dependent variable (menstrual hygiene practice and school absenteeism) which was expressed in the form of Crude Odds Ratio (OR). To judge the strength of association confidence interval (CI) at $95 \%$ was used.

\section{RESULTS}

Out of 321 participant, most participants were of age group 15-19 years. Higher number of students i.e. $60.1 \%$ belonged to joint family, followed by nuclear family with $39.9 \%$. Chettri were higher in number, followed by Dalits, then by Bramhin and other ethnic group includes Shahi. All of the respondents were Hindus. Around $82 \%$ mothers and $40 \%$ fathers of respondents were illiterate. Most common occupation of respondent's mothers and fathers were agriculture which was $65.1 \%$ and $73.5 \%$ respectively (Table 1 ).

Most of the women faced their first menstruation at the age below 15 i.e. $66.7 \%$ whereas 16-19 age group were less i.e. $33.3 \%$. The mean age at menarche was found to be $14.003 \pm 1.085$ (SD) years. From this study it was found that majority of students menstrual hygiene practice was poor i.e. $86.9 \%$ and only $13.1 \%$ of respondents hygiene practice was good. Only $4 \%$ of respondents used sanitary pad whereas $2.2 \%$ of adolescent girls changed their pad every six hours. About $98 \%$ of girls used soap and water during washing cloth and more than half of the girls (54.7\%) dried the reused cloth in sunlight. More than half of the respondent $(69.8 \%)$ said that they dispose the cloth or pad in open area. Less than half of the respondents i.e. $22.7 \%$ used only water while cleaning genitalia. Almost every respondent i.e. $91 \%$ bathed during menstruation. About two third of the adolescent girls (76.6\%) did not sleep in their house during their entire menstrual cycle. About $78.8 \%$ of the total respondents slept outside their 
houses during first menstruation. Almost every adolescent girl i.e. $92.5 \%$ eats outside kitchen during menstruation. Nearly one third $(22.1 \%)$ of the total respondent said that they were absent in school during their last menstruation. About $11.5 \%$ of adolescent girls reported that menstrual problem interferes with their school performance. More than 1 in 10 adolescent girl felt that their academic performance was degraded after than before menarche (Table 2).

\section{Table 1: Socio-Demographic characteristics of the respondent $(n=321)$}

Characteristics

\section{Frequency}

(\%)

Age (Years)

10-14

74

23.1

15-19

247

76.9

Family Type

Nuclear family

128

39.9

Joint family

193

60.0

Ethnicity

Brahmin

71

22.1

Chhetri

109

34.0

Dalits

76

23.7

Janajati

0.9

Others

62

19.3

Education of Mother

Literate

52

Illiterate

No Mother

264

16.2

82.2

1.6

Occupation of Mother

House work

Business

Job

Agriculture

Daily wages

work

No Mother

5

91
6
5
209
5
5

28.3

1.9

1.6

65.1

1.6

1.6

Education of Father

Literate
Illiterate

No Father

181

56.4

40.0

2.8

\section{Occupation of Father}

$\begin{array}{lcc}\text { Business } & 41 & 12.8 \\ \text { Agriculture } & 236 & 73.5 \\ \text { Job wages } & 26 & 8.1 \\ \text { Daily } & 9 & 2.8 \\ \text { Work No Father } & 9 & 2.8 \\ \text { Nor }\end{array}$

Table 2: Menstrual hygiene practice and school absenteeism $(n=321)$

Characteristics

Frequency \%

Age at first

menstruation (years)

$\leq 15$

214

66.7

16-19

107

33.3

Mean

$14.003 \pm 1.085$

(SD)

Median

14

Good practice during

Menstruation

42

13.1

Use of Sanitary pad

13

4.0

Changed absorbent

every 6 hours

7

2.2

Re-use of cloth $(n=308)$

308

100.0

Washing cloth with

soap and water $(\mathrm{n}=308)$

305

98.0

Drying of cloth in open

space $(n=308)$

168

54.7

Disposal of Pad/ Cloth

in open area

224

69.8

Cleaning of Genitalia

using only water

73

22.7

Bathing daily during

Menstrual cycle

292

91.0

Cultural Restriction

Practiced by

respondents

Slept outside house

during Menstruation

(Chhau goth)

Slept outside

house during first

menstruation (Chhau

253

78.8

goth)

Eating outside kitchen

during menstruation

297

92.5

School absenteeism

during last

menstruation

71

22.1

Poor academic perfor-

mance after menarche 
Table 3: Bivariate analysis of menstrual hygiene practice with Socio-Demographic variables

\begin{tabular}{|c|c|c|c|c|c|}
\hline \multirow[b]{2}{*}{ Variables } & \multicolumn{5}{|c|}{ Menstrual hygiene practice } \\
\hline & & $\begin{array}{c}\text { Poor practice } \\
\text { n (\%) }\end{array}$ & $\begin{array}{c}\text { Good practice } \\
\text { n (\%) }\end{array}$ & P-value & $\begin{array}{c}\text { OR } \\
\text { (CI 95\%) }\end{array}$ \\
\hline \multirow[b]{2}{*}{ Age group (years) } & $10-14$ & $152(92.7 \%)$ & $12(7.3 \%)$ & \multirow[b]{2}{*}{$0.002^{*}$} & \multirow[b]{2}{*}{$2.9(1.4-6.0)$} \\
\hline & $15-19$ & 127(80.9\%) & $30(19.1 \%)$ & & \\
\hline \multirow{2}{*}{ Type of family } & Nuclear & 107(83.6\%) & $21(16.4 \%)$ & \multirow{2}{*}{0.151} & \multirow{2}{*}{$\begin{array}{l}0.6(0.3- \\
1.19)\end{array}$} \\
\hline & Joint & $172(89.1 \%)$ & $21(10.9 \%)$ & & \\
\hline \multirow{2}{*}{ Ethnicity } & $\begin{array}{l}\text { Upper caste } \\
\text { group }\end{array}$ & $157(87.2 \%)$ & $23(12.8 \%)$ & \multirow{2}{*}{0.854} & \multirow{2}{*}{$1.0(0.5-2.0)$} \\
\hline & $\begin{array}{l}\text { Disadvantaged } \\
\text { group }\end{array}$ & $122(86.5 \%)$ & $19(13.5 \%)$ & & \\
\hline \multirow{2}{*}{ Mothers education } & Illiterate & $226(85.6 \%)$ & $38(14.4 \%)$ & $\begin{array}{l}0.264 \\
\text { (fisher's }\end{array}$ & \multirow{2}{*}{$0.4(0.1-1.4)$} \\
\hline & Literate & $48(92.3 \%)$ & $4(7.7 \%)$ & $\begin{array}{l}\text { exact } \\
\text { test) }\end{array}$ & \\
\hline \multirow{2}{*}{ Mothers occupation } & $\begin{array}{l}\text { Agricultural } \\
\text { work }\end{array}$ & $258(86 \%)$ & $42(14 \%)$ & \multirow{2}{*}{$\begin{array}{c}0.143 \\
\text { (fisher's } \\
\text { exact } \\
\text { test) }\end{array}$} & \multirow{2}{*}{-} \\
\hline & $\begin{array}{l}\text { Non-agricultural } \\
\text { work }\end{array}$ & $16(100 \%)$ & $0(0 \%)$ & & \\
\hline \multirow{2}{*}{ Fathers education } & Illiterate & 117(89.3\%) & $14(10.7 \%)$ & \multirow{2}{*}{0.410} & \multirow{2}{*}{$1.3(0.6-2.6)$} \\
\hline & Literate & $156(86.2 \%)$ & $25(13.8 \%)$ & & \\
\hline \multirow[t]{2}{*}{ Fathers occupation } & $\begin{array}{l}\text { Agricultural } \\
\text { work }\end{array}$ & $66(86.8 \%)$ & $10(13.2 \%)$ & \multirow[t]{2}{*}{0.842} & \multirow{2}{*}{$0.9(0.4-1.9)$} \\
\hline & $\begin{array}{l}\text { Non-agricultural } \\
\text { work }\end{array}$ & 207(87.7\%) & 29(12.3\%) & & \\
\hline
\end{tabular}

\section{Reference Category 1}

The p-value at confidence level of $95 \%$ is 0.002 for age of respondent which is less than 0.05. Thus, the age of respondent is significantly associated with menstrual hygiene practice. Similarly, adolescent girls of 10-14 age group were three time more likely to have poor practice than those who were between 15-19 years (Table 3).

\section{Reference Category 1}

The p-value at confidence level of $95 \%$ is 0.017 for type of family of respondent which is less than 0.05 . Thus, the factor is significantly associated with menstrual hygiene practice. Similarly, adolescent girls from nuclear families are 1.9 times more likely to be absent from school during the menstrual cycle in comparison to girls from joint families (Table 4).

\section{DISCUSSION}

In this study, the mean age at menarche of respondents was $14.003 \pm 1.085$ whereas in a study conducted in Sunsari, the mean age at menarche was 13.1 years. ${ }^{8}$ In a similar type of study conducted in Chennai, India the mean age at menarche was found to be 12.7 years. ${ }^{11}$ A study conducted in Egypt ${ }^{12}$ showed that mean age of menarche of 17.2 years which was slightly higher compare to our study. Several other studies had similar result as the present study. ${ }^{8,13,14}$

Our study showed that $13.1 \%$ were engaged in good hygiene practice whereas in a study conducted in Doti district ${ }^{15} 40 \%$ were engaged in good menstrual hygiene practices. In our study, $4 \%$ of the adolescent school girls were found using sanitary pad during their menstruation. This finding is in contrast to studies conducted in Northeast Ethiopia ${ }^{7}$ (35.38\%), India ${ }^{16}$ (32.7\%) and Guntur, Andhra Pradesh ${ }^{17}$ (53.70\%). Less use of sanitary pad by our study participants may be because of hesitation and unavailability in the local market. In present study it is seen that most of the girls reused the cloth which is similar to the study done in Northeast Ethiopia?. 
Table 4: Bivariate analysis of School absenteeism during last menstruation with Socio-

Demographic variables

\begin{tabular}{|c|c|c|c|c|c|}
\hline \multirow[b]{2}{*}{ Variables } & \multicolumn{5}{|c|}{$\begin{array}{l}\text { School absenteeism } \\
\text { during last menstruation }\end{array}$} \\
\hline & & Yes n (\%) & No $n(\%)$ & P-value & OR (CI 95\%) \\
\hline \multirow[b]{2}{*}{ Age group (years) } & $10-14$ & $33(20.1 \%)$ & $131(79.9 \%)$ & \multirow[b]{2}{*}{0.378} & \multirow[b]{2}{*}{$0.7(0.4-1.3)$} \\
\hline & $15-19$ & $38(24.2 \%)$ & $119(75.8 \%)$ & & \\
\hline \multirow{2}{*}{ Type of family } & Nuclear & $37(28.9 \%)$ & 91(71.1\%) & \multirow{2}{*}{$0.017^{*}$} & \multirow{2}{*}{$1.9(1.1-3.2)$} \\
\hline & Joint & $34(17.6 \%)$ & $159(82.4 \%)$ & & \\
\hline \multirow{2}{*}{ Ethnicity } & Upper caste group & $38(21.1 \%)$ & $142(78.9 \%)$ & \multirow{2}{*}{0.623} & \multirow{2}{*}{$0.8(0.51-1.4)$} \\
\hline & Disadvantaged group & $33(23.4 \%)$ & $108(76.6 \%)$ & & \\
\hline \multirow{2}{*}{$\begin{array}{l}\text { Mothers } \\
\text { education }\end{array}$} & Illiterate & $60(22.7 \%)$ & $204(77.3 \%)$ & \multirow{2}{*}{0.804} & \multirow{2}{*}{$1.0(0.5-2.2)$} \\
\hline & Literate & $11(21.2 \%)$ & $41(78.8 \%)$ & & \\
\hline \multirow{2}{*}{$\begin{array}{l}\text { Mothers } \\
\text { occupation }\end{array}$} & Agricultural work & $68(22.7 \%)$ & $232(77.3 \%)$ & \multirow{2}{*}{$\begin{array}{c}1.00 \\
\text { (fisher's } \\
\text { exact test) }\end{array}$} & \multirow{2}{*}{$1.2(0.3-4.5)$} \\
\hline & Non-agricultural work & $3(18.8 \%)$ & $13(81.2 \%)$ & & \\
\hline \multirow{2}{*}{$\begin{array}{l}\text { Fathers } \\
\text { education }\end{array}$} & Illiterate & $33(25.2 \%)$ & $98(74.8 \%)$ & \multirow{2}{*}{0.383} & \multirow{2}{*}{$1.2(0.7-2.1)$} \\
\hline & Literate & $38(21.0 \%)$ & $143(79.0 \%)$ & & \\
\hline \multirow{2}{*}{$\begin{array}{l}\text { Fathers } \\
\text { occupation }\end{array}$} & Agricultural work & $14(18.4 \%)$ & $62(81.6 \%)$ & \multirow{2}{*}{0.30} & \multirow{2}{*}{$0.7(0.3-1.3)$} \\
\hline & Non-agricultural work & $57(24.2 \%)$ & 179(75.8\%) & & \\
\hline
\end{tabular}

A study conducted in Guntur, Andhra Pradesh ${ }^{17}$ reported different forms of restrictions observed during menstruation similar to our findings. They found out that $78.99 \%$ girls were not allowed to attend religious occasions and $22.97 \%$ girls were restricted from doing routine household work. In our study among total responses, $97.2 \%$ were not allowed to enter in religious place, $94.7 \%$ girls were not allowed to touch water, $83.5 \%$ were not allowed to sleep in bed and $79.4 \%$ were not allowed to enter in house which shows restriction in doing household work during menstruation.

Regarding the menstrual hygiene, the findings of the present study revealed that more than half of the study sample changed their pad/cloth once a day, a few of them nearly one third (26.5\%) changed it 2-3 times per day. In contrast, study done in Egypt ${ }^{12}$ showed that more than two thirds (69.4\%) of the study sample changed their sanitary pads for three or more times per day and nearly one third (30.6\%) changed it 1 to 2 times per day. Another study conducted in Northeast Ethiopia?,
$58.24 \%$ of girls reported that they changed their menstrual absorbent twice and more than twice respectively.

According to the study conducted in Northeast Ethiopia, ${ }^{7}$ about $37.04 \%$ respondent washed the reusable cloth with soap and water and $33.33 \%$ dried it inside the house in contrast to the present study where $98 \%$ used soap water to clean and $45 \%$ dried it inside the house. A study conducted in Bengaluru, ${ }^{18}$ showed that $29.4 \%$ girls washed the genitals using water only and $70.6 \%$ girls used soap and water to wash their genitals which is analogous to the finding in our study.

In our study, $22.1 \%$ girls did not attend school because of menstruation related problems. Several other studies had different result as compared to our study. ${ }^{13,19,20}$ Moreover, study conducted throughout Africa and Asia ${ }^{21}$ noted that menstrual hygiene practices are poor and many adolescent girls miss school because of period. The reason behind school absenteeism in this study was dysmenorrhea, bleeding and 
backache which is similar to the study conducted in Bangladesh. ${ }^{20}$

Almost every adolescent girl practiced restriction in their house. In this study majority of students (76.6\%) slept outside house during menstruation in a room commonly known as Chhau Goth which is similar to the finding of study conducted in far-western Nepal. ${ }^{22}$ Study conducted in Far-westconcluded that around 85\% practiced Chaupadi (tradition in Nepali community where women are not allowed to do normal daily activities and are banished to sleep outside house during menstruation period) which is slightly higher than our study. It appears that education and awareness about the menstrual cleanliness practice was poor in that community. ${ }^{23}$

In conclusion, this study revealed that among the adolescent girls of the study zone, the general menstrual cleanliness practice was poor. Almost every adolescent girls practiced restriction in their houses. It appears that education and awareness about the menstrual cleanliness practice was poor in that community. School absenteeism and degradation in academic performance was seen after menarche. Similarly, late adolescent girls were more likely to have good menstrual hygiene practice than early adolescent.

\section{ACKNOWLEDGEMENTS}

We would like to express hearty thanks to all the respondents involved in the data collection and school teachers for their valued contribution in the research. Special thanks to NHRC for ethical approval for the research and Om Health Campus for providing this opportunity.

\section{Conflict of Interest:}

Poster Presentation at Fifth National Summit of Health and Population Scientists in Nepal, NHRC

\section{REFERENCES}

1. DE Adinma, JIB Adinma. Perceptions and Practices on Menstruation Amongst Nigerian Secondary School Girl. Afr J Repro Health 2008; 12: 74-83.

2. Adhikari P, Kadel B, Dhungel SI, Mandal A. Knowledge and practice regarding menstrual hygiene in rural adolescent girls of Nepal. Kathmandu Univ Med J 2007; 5: 382-6.

3. Amaza D. Menstrual Pattern among Female Medical Students in University of Maiduguri, Nigeria. British J Med Med Res 2012; 2: 327-37.

4. Maji. S. A study on menstrual knowledge and practices among rural adolescent girls in Burdwan district, Westbengal. Int'lJ Adv Res 2016; 4: 896-902.

5. Grant MJ, Lloyd CB, Mensch BS. Menstruation and School Absenteeism: Evidence from Rural Malawi. Comp Educ Rev 2013; 57: 260-84.

6. Menstrual Hygiene Matters. [Internet]. 2013. Available from: http://www.wash-united.org/ourwork/issues/menstrual-hygiene-management/ articles/our-work-issues-menstrual-hygienemanagement.

7. Tegegne TK, Sisay MM. Menstrual hygiene management and school absenteeism among female adolescent students in Northeast Ethiopia. BMC Public Health 2014; 14: 1118.

8. Sapkota D, Sharma D, Budathoki SS, Khanal VK, Pokharel HP. Knowledge and practices regarding menstruation among school going adolescents of rural Nepal. J Kathmandu Med Coll 2013; 2: 1-5.

9. Abera Y. Menarche, Menstruation Related Problems and Practices Among Adolescent High School Girls in Addis Ababa. MPH thesis: Addis Ababa University. Department of Community Health 2004.
10. Taffa N, Haimanot $\mathrm{R}$, Desalegn S, Tesfaye A, Mohammed K. Do parents and young people communicate on sexual matters? The situation of Family Life Education (FLE) in a rural town in Ethiopia. Ethiopian J Health Dev 1999; 13: 205-10.

11. Parameaswari PJ, Udayshankar PM, Cynthia S, Vidhyashree MD, Abiselvi A, Sultan SI. A School Survey to Assess Menstrual Hygiene Practices Among Teenage Girls in Chennai, India. MiddleEast J Sci Res 2014; 21: 1448-53.

12. Abd El-Hameed N, Mohamed MS, Ahmed Nh, Ahmed ER. Assessment of Dysmenorrhea and Menstrual Hygiene Practices among Adolescent Girls in Some Nursing Schools at EL-Minia Governorate, Egypt. $J$ Am Sci 2011; 7: 216-23.

13. Zegeye DT, Megabiaw B, Mulu A. Age at menarche and the menstrual pattern of secondary school adolescents in northwest Ethiopia. BMC Womens Health 2009; 9: 29.

14. Khanna A, Goyal RS, Bhawsar R. Menstrual practices and reproductive problems: A study of adolescent girls in Rajasthan.J Health Management 2005; 7: 91-107.

15. Yadav RN, Joshi S, Poudel R, Pandeya P. Knowledge, Attitude, and Practice on Menstrual Hygiene Management among School Adolescents. J Nepal Health Res Counc 2018; 15: 212-6.

16. Bachloo T, Kumar R, Goyal A et al. A study on perception and practice of menstruation among school going adolescent girls in district Ambala Haryana, India. Int'l J Comm Med Pub Health 2016; 3: 931-7.

17. Jogdand K, Yerpude P. A community based study on menstrual hygiene among adolescent girls. Indian J Mat Child Health 2011; 13: 1-6. 
18. Srinivasa S, Manasa G. Menstrual Hygiene among School going Adolescent girls. Int'l J Gen Pediatr Med 2017; 2: 11-6.

19. Sharma P, Malhotra C, Taneja DK, Saha R. Problems related to menstruation amongst adolescent girls. Indian J Pediatr 2008; 75: 125-9.

20. Alam MU, Luby SP, Halder AK et al. Menstrual hygiene management among Bangladeshi adolescent schoolgirls and risk factors affecting school absence: results from a cross-sectional survey. BMJ Open 2017; 7: e015508. doi: 10.1136/ bmjopen-2016-015508
21. House S, Mahon T, Cavill S. Menstrual Hygiene Matters: A resource for improving menstrual hygiene around the world 2013.

22. Amatya P, Ghimire S, Callahan KE, Baral BK, Poudel KC. Practice and lived experience of menstrual exiles (Chhaupadi) among adolescent girls in farwestern Nepal. PloS one 2018; 13: e0208260. https:// doi.org/10.1371/journal.pone.0208260

23. Field Bulletin: Chaupadi in the Far-West: United Nations Resident and Humanitarian Coordinator's Office 2011. 